\title{
Vastus Medialis Muscle
}

National Cancer Institute

\section{Source}

National Cancer Institute. Vastus Medialis Muscle. NCI Thesaurus. Code C117736.

The portion of the quadriceps femoris muscle group that extends medially from the intertrochanteric line of the femur to the medial aspects of the quadriceps femoris tendon and patella. 